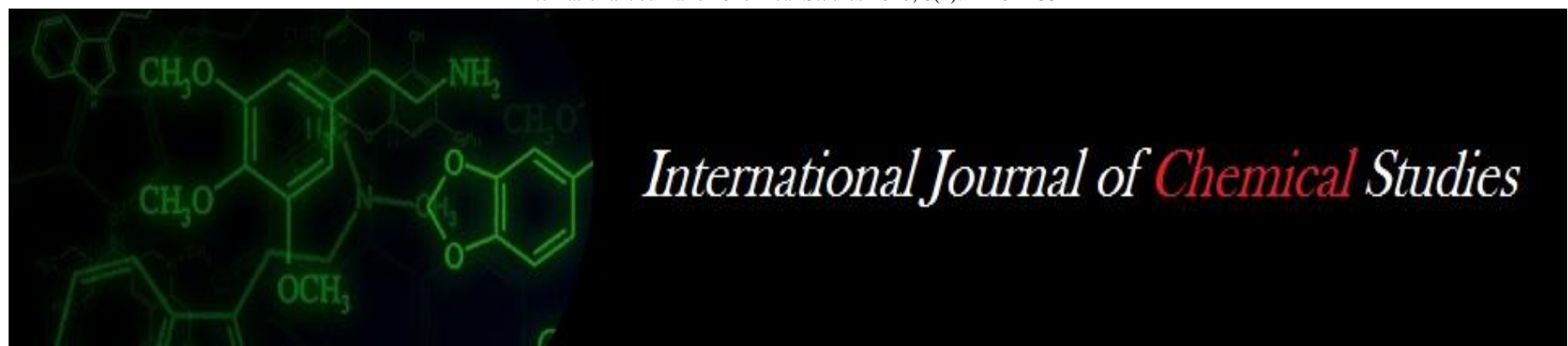

P-ISSN: 2349-8528

E-ISSN: 2321-4902

IJCS 2020; 8(1): 2246-2253

(C) 2020 IJCS

Received: 25-11-2019

Accepted: 27-12-2019

Gursimran Singh Sangha Former PhD Student, Deptt. of Processing and Food Engineering, PAU Ludhiana, Punjab, India

Gagandeep Kaur Sidhu Senior Research Engineer, Deptt. of Processing and Food Engineering, PAU Ludhiana, Punjab, India

Corresponding Author: Gursimran Singh Sangha Former PhD student, Deptt. of Processing and Food Engineering, PAU Ludhiana, Punjab, India

\section{Optimization of process parameters for microwave assisted extraction of stevioside from Stevia rebaudiana (Bertoni) leaves}

\author{
Gursimran Singh Sangha and Gagandeep Kaur Sidhu
}

DOI: https://doi.org/10.22271/chemi.2020.v8.i1ah.8607

\begin{abstract}
Microwave assisted extraction process was employed for the extraction of stevioside from dry stevia leaf powder. The independent factors were leaf to water ratio (1:5 to 1:25), extraction time (0.5 to $2 \mathrm{~min})$, and microwave power level (180 to 900 watt). The pooled effect of these independent factors on the stevioside content, color and TSS of the extract was studied. For optimizing the extraction process, boxbehnken design in amalgamation with response surface methodology was employed. Significant regression models with coefficient of determination greater than 0.80 were established to evaluate the effect of independent factors on the responses. The optimum extraction conditions are: microwave power level: 454-watt, extraction time: $1.13 \mathrm{~min}$ and leaf to water ratio: 1:25 $(\mathrm{g}: \mathrm{mL})$. The maximum predicted values for stevioside content at optimum conditions was $9.37 \%$.
\end{abstract}

Keywords: Stevioside, microwave assisted, stevia, optimization, stevia, response surface methodology

\section{Introduction}

Stevia rebaudiana Bertoni is a Paraguayan herb which is also known as "Ka-Hee" or "hierba dulce" (sweet herb) which is a bountiful source of natural sweeteners called as steviol glycosides. Steviol glycosides i.e stevioside and rebaudioside-A are organic components that have active hydrophilic and hydrophobic glycoside groups respectively. Stevioside is the main steviol glycoside extracted from stevia (Carakostas et al. 2012). Recently the extraction of stevioside has attained immense interest among researchers (Chranioti et al. 2016) ${ }^{[3]}$. Stevia sweeteners are being used world over in a range of food formulations and for different pharmaceutical applications. The use of Stevia extract has been approved for several years in Brazil, Argentina, and Paraguay, as well as in China, Korea, and Japan to sweeten soft drinks, soy sauce and yogurt. Stevia has been found safe for diabetics, as it does not influence blood sugar levels. It does not have any neurological or renal side effects in contrast to other synthetic sweeteners. Stevia has vast anti-fungal and anti-bacterial properties. Stevia extract can be safely used in herbal medicines, tonics for diabetic patients and also in daily usage products such as mouthwashes and toothpastes. Mild stevia leaf tea offers admirable help for an upset stomach. Numerous scientific studies on the processing of stevia for the extraction of stevioside and rebaudioside-A are available along with mammoth number of Japanese patents focusing on this area. The processing of stevia leaves essentially involves extraction, separation, filtration, crystallization and drying. Most of the known processes require the use coagulating agents and organic solvents. Some of the popular processes employ chromatographic separation techniques and chelating agents followed by solvent extraction (Kumar, 1986) ${ }^{[8]}$. Also, an extraction method requiring pre-treatment of the extract with lime and the use of ion exchange columns has been studied (Giovaneto 1990). Tan et al. (1988) [11] extracted stevia glycosides by using supercritical fluid extraction technique with carbon dioxide. Midmore and Rank (2006) ${ }^{[9]}$ studied that hot boiling water extraction attained 9398\% extraction of stevioside from stevia leaf powder. Nevertheless, hot water extraction was associated with long extraction time and high temperatures. Yoda et al. (2003) ${ }^{[12]}$ also studied the supercritical fluid extraction and the kinetics of the glycosides from stevia leaves. Pol et al. (2007) ${ }^{[10]}$ reported a pressurized fluid extraction technique for the extraction of stevioside from $S$. rebaudiana using methanol. 
Microwave assisted extraction is gaining popularity because it allows faster extraction, reduced solvent, increases recovery, saves time and energy consumption in comparison to conventional methods of extraction.

The existing extraction methods study one variable at a time, but in extraction process there are numerous independent variables affecting the extraction process. Therefore, it is essential to involve optimization techniques for optimization of different process parameters of microwave assisted extraction of stevioside from stevia leaves. Numerical optimization employs response surface methodology for this practice. RSM is a compilation of statistical and mathematical techniques useful for the developing, improving, and optimizing process. RSM has been extensively used to assess and realize the interactions between different process parameters. RSM comprises of different phases such as determination of various independent factors and their effective levels, choice of the experimental design, prediction and verification of model equations, generating response surfaces and contour plots and finally determination of optimum points. In this process, the investigational design phase leads to a proficient testing for assessment of the process for laboratory level investigation. The benefit of employing RSM is that it takes into consideration the interactive effects of independent factors in the process and thus the amount of trials reduces. Recently RSM has been fruitfully used by various researchers for optimizing extraction processes involving wide variety of raw materials. Considering all these facts into thought the present work is centered on learning the pooled effect of microwave power level, extraction time and leaf to water ratio on the stevioside concentration and color of the stevia extract, and to optimize the process parameters for maximum extraction of stevioside from the stevia leaf powder using RSM.

\section{Materials and Methods \\ Preparation of stevia extract}

Dehydrated stevia leaves were procured from Green Valley Farms, Punjab. Water was used as solvent for microwave assisted extraction of stevia. A specific ratio of stevia leaf powder to water (weight to volume) was measured and the stevia powder was mixed with water. The sample was exposed to a specific microwave power level for a fixed duration of time in a laboratory microwave. After the completion of microwave exposure process, the stevia extract was cooled and then filtered using whatman filter paper and finally analyzed for different quality parameters.

\section{Quality parameters of extract}

The stevioside content of the stevia extract derived after different microwave assisted extraction treatments was calculated by method described by (Kaur, 2009) ${ }^{[7]}$. Steviol glycoside extract was hydrolyzed with $5 \mathrm{~N} \mathrm{HCl}$ at $70^{\circ} \mathrm{C}$ for 1 hour and the glucose units released from the stevioside upon hydrolysis were calculated by Dubois et al. (1956) ${ }^{[5]}$. The concentration of glucose was multiplied by a factor of 1.64 (on the basis of molecular weight) to estimate stevioside content. Color of the obtained extract was measured in terms of optical absorbance $\left(\mathrm{A}_{420}\right)$ at a wavelength of $420 \mathrm{~nm}$ using spectrophotometer. The total soluble solids $\left({ }^{\circ} \mathrm{Bx}\right)$ were determined using Erma hand refractometer.

\section{Experimental design}

To study the effect of independent factors on the responses within the range of study, RSM was employed. Three independent factors selected for the optimization process were microwave power level (180 to $900 \mathrm{Watt})$, exposure time $(0.5$ to 2 minutes) and stevia leaf powder to water ratio (1:5 to 1:25). After selection of independent factors and their ranges, experimental trials were generated by Design Expert software (Version 9.0, Statease, Minneapolis, MN, USA). In the present study a three-level design recommended by Box and Behnken (1960) [1] was employed and response surface methodology was utilized to observe the linear, quadratic and interactive effects of microwave power level, extraction time and stevia leaf powder to water ratio on three responses namely stevioside content, color of extract and TSS. A total of 17 experimental runs were carried. The design was a threelevel incomplete factorial design for estimation of parameters in a second order model. A second order polynomial equation was used to evaluate the yield as response $\left(\mathrm{y}_{\mathrm{k}}\right)$, which is a function of three independent factors $\left(\mathrm{x}_{\mathrm{i}}\right)$, namely extraction time, microwave power level and leaf powder to water ratio as discussed below:

$y_{k}=\beta_{0}++\sum_{i=1}^{n} \beta_{i} x_{i}+\sum_{i=1}^{n} \beta_{i i} x_{i}^{2}+\sum_{i=1}^{n-1} \sum_{j=i+1}^{n} \beta_{i j} x_{i} x_{j}$

Where, $\beta_{0}$ is the value of the fitted response at the centre point of the design, i.e. point $(0,0)$ and $\beta_{\mathrm{i}}, \beta_{\mathrm{ii}}$ and $\beta_{\mathrm{ij}}$ are the linear, quadratic and interactive regression terms, respectively. The term $\mathrm{xi}$ denotes the coded independent variables. The regression coefficients of linear, quadratic, and interaction terms in the model and their effect were examined by generating an analysis of variance (ANOVA) table. All the terms of the model were evaluated statistically by calculating the F-values at probability levels (p) of 0.01 and 0.05 . The satisfactoriness of the developed models was analyzed by executing lack of fit test, model analysis, and coefficient of determination $\left(\mathrm{R}^{2}\right)$ analysis. $\mathrm{R}^{2}$ ranges from 0 to 1 which is the measure of degree of fit and higher values of this coefficient are sought-after. It is used for describing the proportion of the unpredictability in the data explained by the analysis of variance model. A significant lack of fit (small probability value) signifies that the model may not adequately fit the data. After fitting the models, the generated data was utilized for plotting contour plots and response surfaces. The models were considered adequate when the calculated F-ratio was more than the table F-value and lack of fit test was insignificant.

Optimization of fitted polynomials for the response variables was carried out through nonlinear mathematical optimization method using Design Expert software. Surface plots were created from the fitted quadratic polynomial regression equations in order to visualize the relationship among the factors and responses and to obtain the numerical solution for optimum conditions for variables at desired response levels. The contour plots for the models were plotted as a function of the two variables, while keeping the other one at optimum level.

\section{Results and Discussion}

The independent factors in terms of their actual and coded values have been shown in Table 1 . The various combinations of design factors with their respective responses are given in Table 2. After fitting the second order polynomial model for the three responses, regression analysis was completed and an ANOVA table was prepared. 
Table 1: Experimental range and levels of the independent factors

\begin{tabular}{|c|c|c|c|}
\hline \multirow{2}{*}{ Coded Values } & \multicolumn{3}{|c|}{ Actual Values } \\
\cline { 2 - 4 } & Time (Minutes) & Power (Watts) & $1: 5$ \\
\hline-1 & 0.5 & 180 & $1: 15$ \\
\hline 0 & 1.25 & 540 & $1: 25$ \\
\hline+1 & 2 & 900 & (g:ml) \\
\hline
\end{tabular}

Table 2: Experimental conditions and responses for three variables for stevioside extraction

\begin{tabular}{|c|c|c|c|c|c|c|}
\hline \multirow{2}{*}{ Experiment No. } & \multicolumn{3}{|c|}{ Responses } \\
\cline { 2 - 7 } & A: Time (min) & B: Power (Watts) & C: Ratio (g:ml) & Stevioside Content (\%) & A420 & TSS $\left({ }^{\circ}\right.$ Brix) \\
\hline 1 & $0.50(-1)$ & $540(0)$ & $1: 25(+1)$ & 8.3 & 1.113 & 6.9 \\
\hline 2 & $0.50(-1)$ & $180(-1)$ & $1: 15(0)$ & 6.2 & 1.115 & 6.7 \\
\hline 3 & $1.25(0)$ & $180(-1)$ & $1: 5(-1)$ & 6.5 & 1.190 & 8.5 \\
\hline 4 & $0.50(-1)$ & $540(0)$ & $1: 5(-1)$ & 8.2 & 1.387 & 6.6 \\
\hline 5 & $1.25(0)$ & $540(0)$ & $1: 15(0)$ & 10.7 & 1.258 & 8.1 \\
\hline 6 & $2.00(+1)$ & $540(0)$ & $1: 25(+1)$ & 7.5 & 1.124 & 8.4 \\
\hline 7 & $1.25(0)$ & $540(0)$ & $1: 15(0)$ & 9.3 & 1.254 & 8.8 \\
\hline 8 & $1.25(0)$ & $540(0)$ & $1: 15(0)$ & 9.9 & 1.256 & 8.3 \\
\hline 9 & $1.25(0)$ & $540(0)$ & $1: 15(0)$ & 10.3 & 1.289 & 8.4 \\
\hline 10 & $2.00(+1)$ & $180(-1)$ & $1: 15(0)$ & 5.5 & 1.255 & 9.3 \\
\hline 11 & $1.25(0)$ & $900(+1)$ & $1: 5(0)$ & 8.5 & 1.398 & 9.6 \\
\hline 12 & $1.25(0)$ & $180(-1)$ & $1: 25(+1)$ & 6.9 & 1.112 & 7.3 \\
\hline 13 & $1.25(0)$ & $900(+1)$ & $1: 25(+1)$ & 9.1 & 1.396 & 9.5 \\
\hline 14 & $0.50(-1)$ & $900(+1)$ & $1: 15(0)$ & 7.9 & 1.399 & 8.9 \\
\hline 15 & $2.00(+1)$ & $540(0)$ & $1: 5(-1)$ & 6.1 & 1.356 & 9.3 \\
\hline 16 & $1.25(0)$ & $540(0)$ & $1: 15(0)$ & 9.2 & 1.288 & 8.7 \\
\hline 17 & $2.00(+1)$ & $900(+1)$ & $1: 15(0)$ & 6.1 & 1.445 & 11.1 \\
\hline
\end{tabular}

The coefficient of variation, lack of fit, F-value, $\mathrm{R}^{2}$ and regression coefficient of the second order polynomial model are represented in Table 3. The significance of each term was judged by evaluating them against their $\mathrm{p}$ values (probability). The analysis of variance established that for all the responses (stevioside concentration, color and TSS) the models were significant. The values of coefficient of determination $\left(\mathrm{R}^{2}\right)$ for all the responses were more than 0.80 , indicating that a high share of variation was justified by the data and the models were satisfactory. The fitness of model is calculated statistically by confirming the lack of fit of the model. Lack of fit was insignificant in all the experimental conditions demonstrating that the developed models can be used successfully for forecasting the responses. The unexplained variability in the data is given by the coefficient of variation (CV) which is measured as a percentage of the mean of the response variable. Low values of $\mathrm{CV}$ for stevioside content $(\mathrm{CV}=6.92)$, color $(\mathrm{CV}=4.38)$ and $\mathrm{TSS}(\mathrm{CV}=3.14)$ signify that the accuracy and consistency by which the experiments were conducted.

Table 3: The regression coefficients of the second-order polynomial model for the response functions (stevioside and color) in coded level

\begin{tabular}{|c|c|c|c|c|c|c|}
\hline \multirow{2}{*}{ Coefficients } & \multicolumn{3}{|c|}{ F-values } & \multicolumn{3}{|c|}{ Coefficients values } \\
\hline & Stevioside Content (\%) & Color (A420) & TSS & Stevioside Content (\%) & Color (A420) & TSS \\
\hline Model & 14.17 & 17.51 & 32.87 & 9.88 & 1.27 & 8.46 \\
\hline A-Time & $11.86^{*}$ & 1.11 & $141.89 * *$ & -0.67 & 0.021 & 1.13 \\
\hline B-Power & $17.19 * *$ & $37.59 * *$ & $93.35 * *$ & 0.81 & 0.12 & 0.91 \\
\hline C- Ratio & 2.54 & $13.83 * *$ & $6.32 *$ & 0.31 & -0.073 & -0.24 \\
\hline AB- (Time*Power) & 0.98 & - & 0.56 & -0.28 & - & -0.10 \\
\hline AC- (Time*Ratio) & 1.38 & - & 5.05 & 0.32 & - & -0.30 \\
\hline BC- (Power*Ratio) & 0.033 & - & 4.24 & 0.050 & - & 0.28 \\
\hline $\mathrm{A}^{2}-\left(\right.$ Time $\left.^{2}\right)$ & $46.40 * *$ & - & 2.19 & -1.84 & - & -0.19 \\
\hline $\mathrm{B}^{2}-\left(\right.$ Power $\left.^{2}\right)$ & $35.75 * *$ & - & $31.66 * *$ & -1.62 & - & 0.73 \\
\hline $\mathrm{C}^{2}-\left(\right.$ Ratio $\left.^{2}\right)$ & 3.64 & - & $12.90 * *$ & -0.51 & - & 0.47 \\
\hline $\mathrm{R}^{2}$ & 0.95 & 0.80 & 0.98 & - & - & - \\
\hline Adj $R^{2}$ & 0.88 & 0.75 & 0.95 & - & - & - \\
\hline C.V. & 6.92 & 4.38 & 3.14 & - & - & - \\
\hline
\end{tabular}

\section{Stevioside}

Stevioside extraction was significant at probability level $p<0.05$ and $p<0.01$ for first order terms of extraction time and microwave power level respectively. The Model F-value of 14.17 implied that the model is significant. Lack of fit was not significant. The Predicted R-Squared of 0.74 is in reasonable agreement with the Adjusted R-Squared of 0.88 . The stevioside content ranged from 5.5 to $10.7 \%$. The linear term of time was significant $(P<0.05)$ with a negative coefficient indicating decrease in stevioside with increasing time, however, linear term of power was significant $(P<0.01)$ with a positive coefficient indicating increase in extraction with increase in power level. The linear term of ratio (leaf powder: water) was insignificant but with a positive coefficient. All the power terms were observed to be insignificant. The quadratic terms of time and temperature were significant $(P<$ 
0.01 ) and that of ratio were insignificant. All the quadratic terms in the mode were observed to have negative coefficients.

The regression equation of the model showing the cumulative effect of independent factors on stevioside extraction is given as:

Stevioside Content $=9.88-0.67 * \mathrm{~A}+0.81 * \mathrm{~B}+0.31 * \mathrm{C}-$ $0.28 * \mathrm{AB}+0.32 * \mathrm{AC}+0.050 * \mathrm{BC}-1.84 * \mathrm{~A}^{2}-1.62 * \mathrm{~B}^{2}-$ $0.51 * \mathrm{C}^{2}$

Stevioside content was found to increase upto extraction time of $1.12 \mathrm{~min}$ and decreased sharply from $1.12 \mathrm{~min}$ to $2 \mathrm{~min}$ as compared to early increase from 0.5 to $1.12 \mathrm{~min}$. Stevioside content was lower when extraction time was 2 min in comparison to when the extraction time was $0.5 \mathrm{~min}$. Analogous trend was exhibited with power, though increase was more when power was increased from 180 to 635 watt and decreased sharply after microwave power was 635 watts. Leaf powder-water ratio was examined to have inconsequential impact on stevioside content as compared with time and power. However, the stevioside increased with increase in leaf-water ratio from 1:5 to $1: 18$ and decrease thereafter. Least stevioside content $(5.5 \%)$ was achieved when extraction factors (extraction time, microwave power and ratio) were $2 \mathrm{~min}, 180$ watt and 1:15. Maximum stevioside content of $10.7 \%$ was obtained when extraction conditions were $1.25 \mathrm{~min}, 540$ watt and 1:15 respectively. Interactive result of increased power level and extraction time decreased stevioside content considerably when both were increased and ratio was kept at centre point (1:15). At constant power level (540 watt) stevioside content raised with increase in time and leaf-water ratio and decreased after a threshold was reached. Akin trend was observed with increasing power and ratio when time was a constant factor. Figures 1, 2, and 3 represent a three-dimensional plot representing the variation of stevioside concentration with respect to any two factors when other factor was kept constant at centre point.

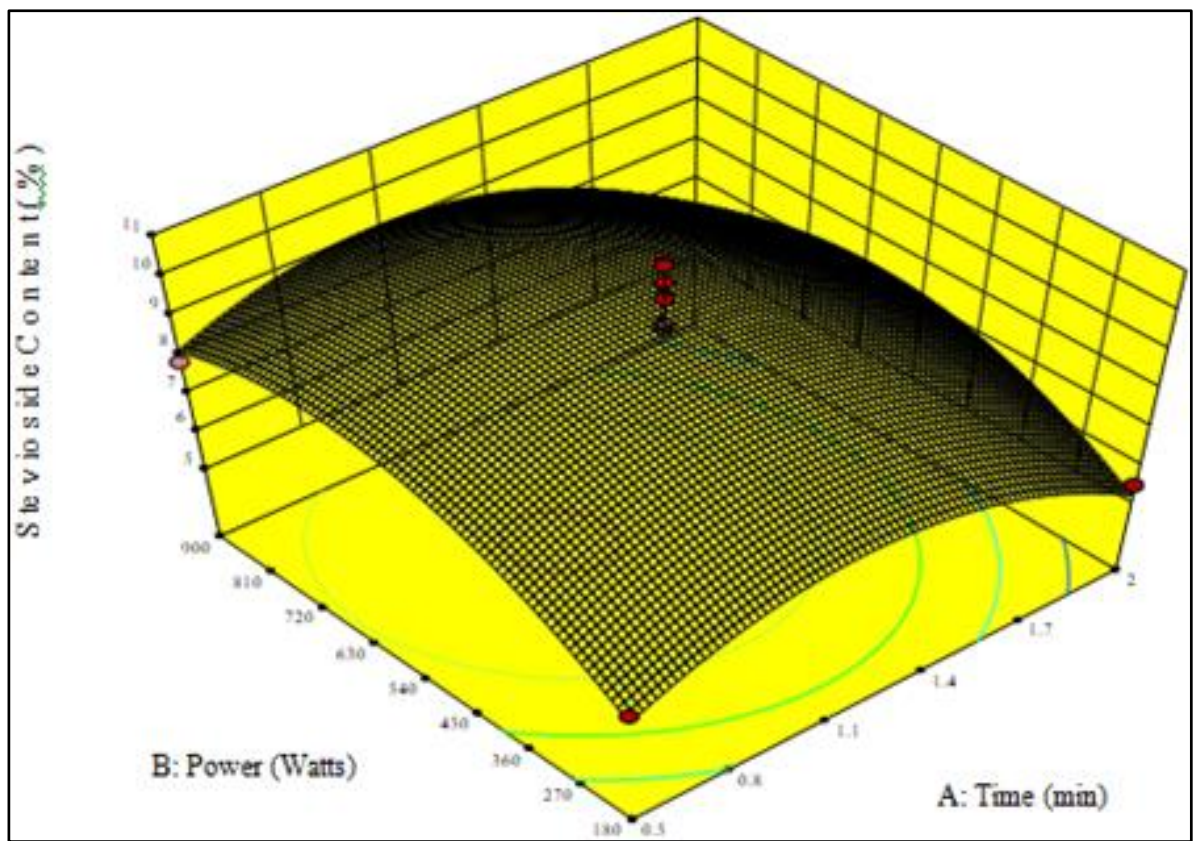

Fig 1: Response surface plot for stevioside as a function of power and time (leaf to water ratio kept constant at centre point).

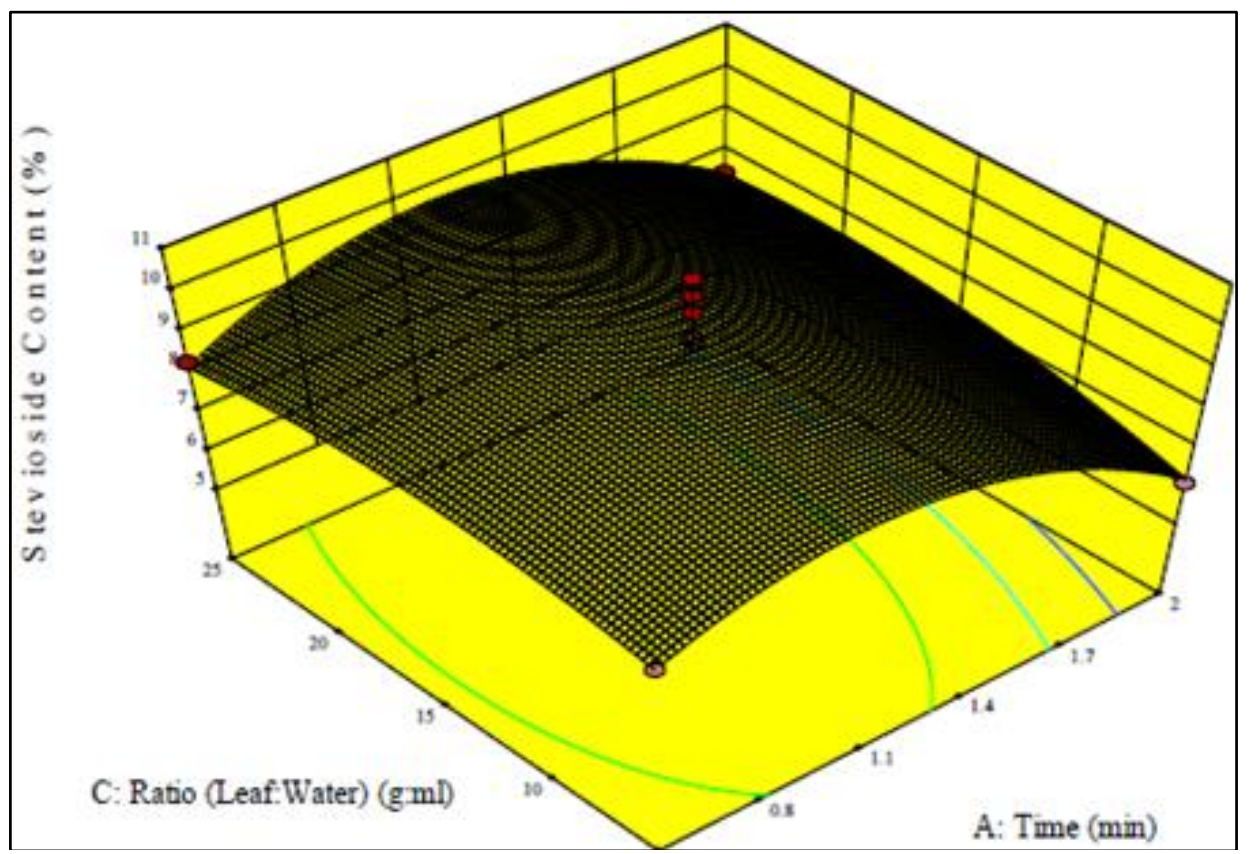

Fig 2: Response surface plot for stevioside as a function of ratio and time (power kept constant at centre point). 


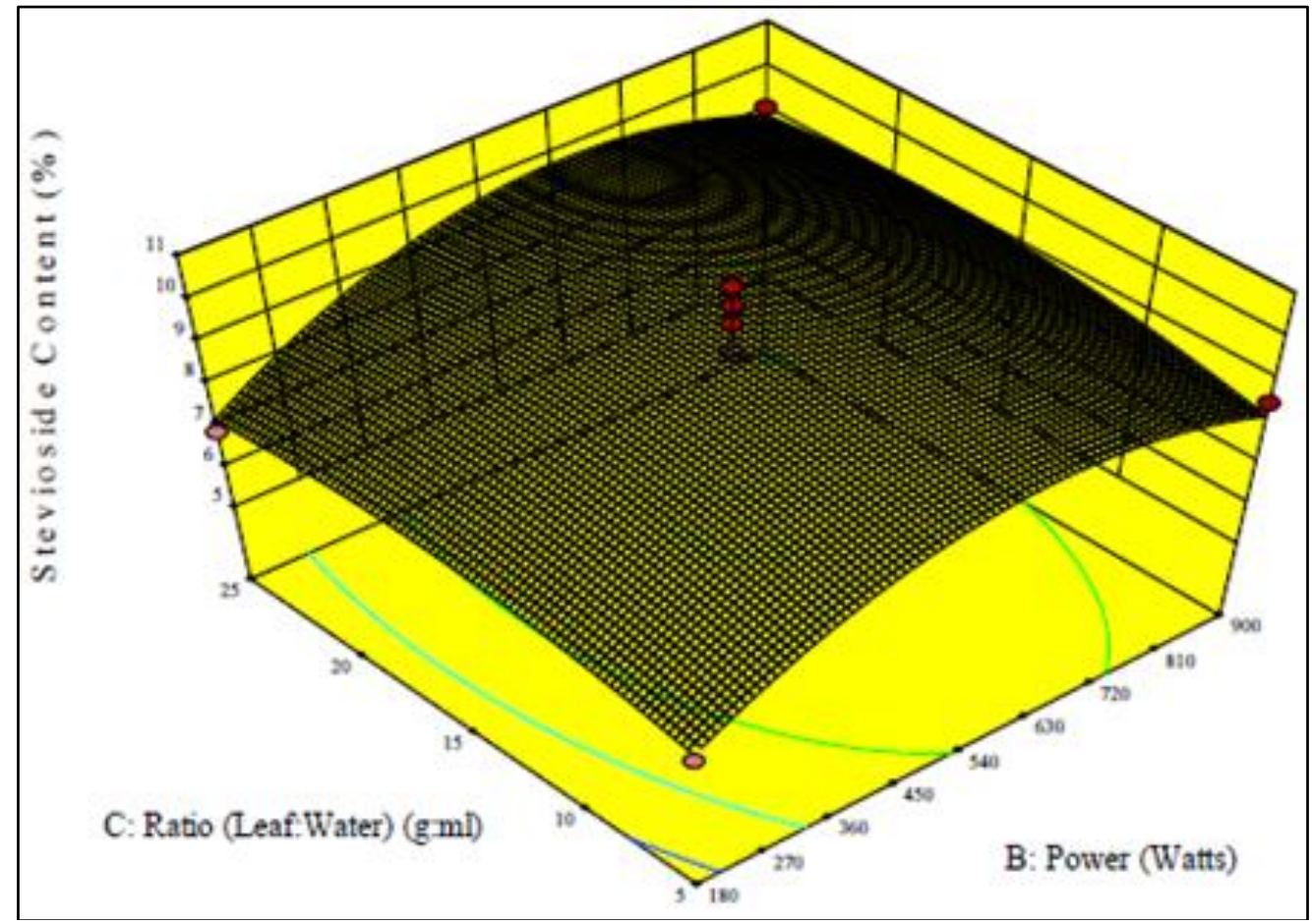

Fig 3: Response surface plot for stevioside as a function ratio and power (time kept constant at centre point).

\section{Color}

Color of stevia extract was significant at probability level $p<0.01$ for first order terms of microwave power level and power ratio. The Model F-value of 17.51 implied the model is significant. The value of coefficient of determination $\left(\mathrm{R}^{2}\right)$ was found to be 0.80 . The $\mathrm{A}_{420}$ ranged from 1.112 to 1.445 throughout the extraction process. The linear term of time was observed to be insignificant. Microwave power level had positive effect and ratio had a negative effect on color as indicated by positive and negative coefficients respectively. The regression equation of the model showing the cumulative effect of independent factors on color of extract is given as:

$\mathrm{A}_{420}=1.27+0.021 * \mathrm{~A}+0.12 * \mathrm{~B}-0.073 * \mathrm{C}$

The color $\left(\mathrm{A}_{420}\right)$ of extract increased faintly with extraction time from 0.5 to $2 \mathrm{~min}$ and sharply with power level from 180 to 900 watt. With increase in leaf-water ratio from 1:5 to 1:25 the color value decreased. Least value $\mathrm{A}_{420}$ of 1.112 was obtained when extraction conditions were $1.25 \mathrm{~min}, 180$ watt and 1:25 and the highest value of $\mathrm{A}_{420}$ of 1.445 was obtained when extraction conditions were 2 min, 900 watt and 1:15. The interactive effect of time and ratio reduced color value when power level was kept constant. Time and power had a synergetic effect on extract color value when ratio was at centre point of 1:15. Interaction of power and leaf-water ratio with time as constant at $1.25 \mathrm{~min}$ (centre point) reduced color value. The dominant influence of microwave power level in increasing color value of extract was due to the fact that higher microwave power level facilitates higher extraction of pigments. Figures 4, 5, and 6 represent a three-dimensional plot representing the variation of color of extract with respect to any two factors when other factor was kept constant at centre point.

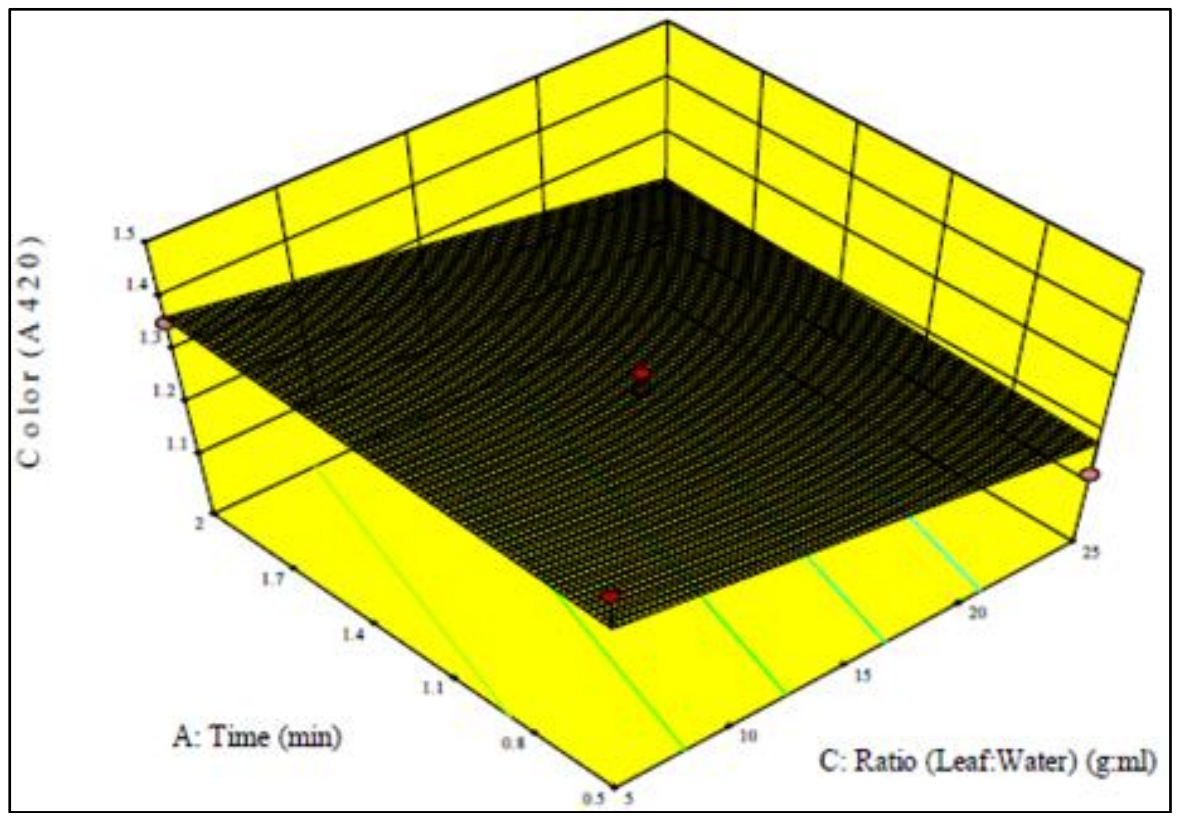

Fig 4: Response surface plot for color as a function of time and ratio (power kept constant at centre point) 


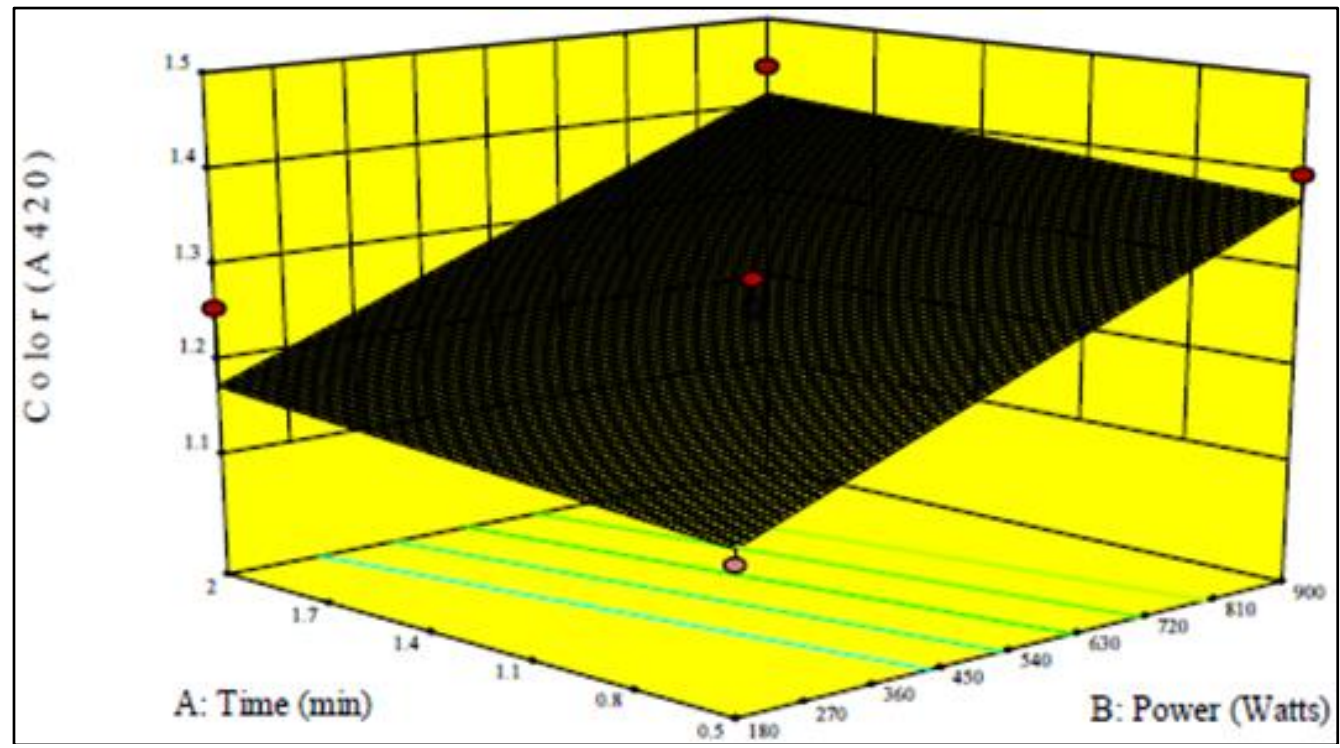

Fig 5: Response surface plot for color as a function of time and power (ratio kept constant at centre point).

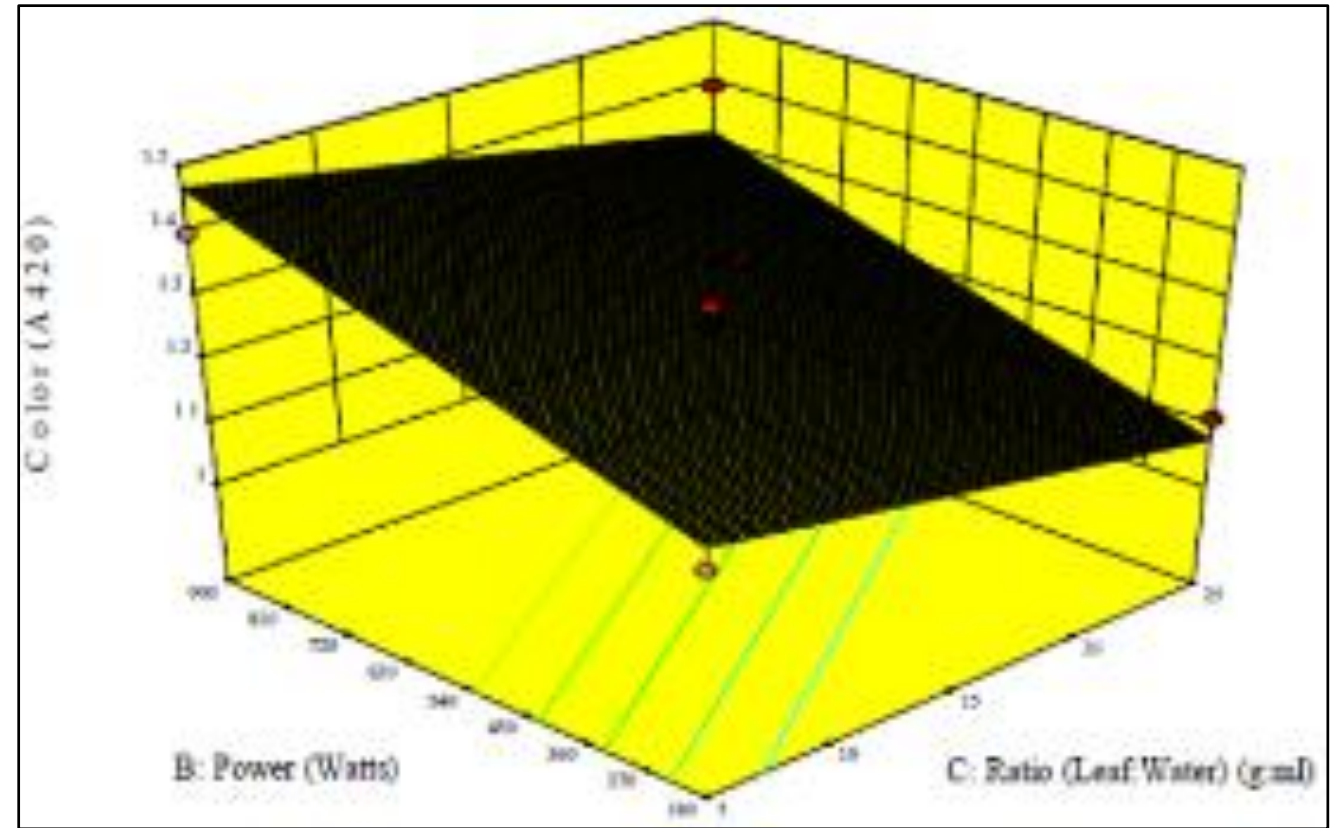

Fig 6: Response surface plot for color as a function of power and ratio (time kept constant at centre point).

\section{TSS}

TSS of stevia extract was significant at probability level $p<0.01$ for first order terms of microwave power level and extraction time and significant at probability level $p<0.05$ for first order terms of ratio. The Model F-value of 32.87 implied that the model is significant. The value of coefficient of determination $\left(\mathrm{R}^{2}\right)$ was found to be 0.98 . The TSS ( ${ }^{\circ}$ Brix) ranged from 6.6 to 11.1 throughout the experiment. All power terms and quadratic term of extraction time were insignificant.

The regression equation of the model showing the cumulative effect of independent factors on TSS of extract is given as:

$\mathrm{TSS}=8.46+1.13 * \mathrm{~A}+0.91 * \mathrm{~B}-0.24 * \mathrm{C}-0.10 * \mathrm{AB}-$ $0.30 * \mathrm{AC}+0.28 * \mathrm{BC}-0.19 * \mathrm{~A}^{2}+0.73 * \mathrm{~B}^{2}-0.47 * \mathrm{C}^{2}$

It was observed that TSS of stevia extract increased with increase of extraction time from 0.5 to $2 \mathrm{~min}$. TSS of extract decreased with increase in power level upto 327 watt and increased thereafter. TSS increased when leaf-water ratio increased from 1:5 to 1:12.9 and decreased subsequently.
Lowest value of TSS of $6.6^{\circ}$ Brix was achieved when extraction conditions were $0.5 \mathrm{~min}, 540$ watt and 1:5 and highest TSS of $11.1^{\circ}$ Brix was achieved when time, power and leaf-water ratio were $2 \mathrm{~min}, 900 \mathrm{watt}$ and 1:15 respectively. Interaction of extraction time and power level increased TSS value when leaf-water ratio was at 1:15 (centre point). TSS of extract was high when time and power both were at their highest values ( 2 min and 900 watt) and ratio was held constant as compared to highest value of extraction time (2 min) or power level (900 watt) only. Interaction of time and ratio with power at centre point (540 watts) gradually increased TSS. Analogous increase in TSS was observed in case of interaction of power level and ratio with constant time of $1.25 \mathrm{~min}$. The influence of power with time as well as ratio was more pronounced than any other interactive effect. Figures 7, 8, and 9 represent a three-dimensional plot representing the variation of TSS of extract with respect to any two factors when other factor was kept constant at centre point. 


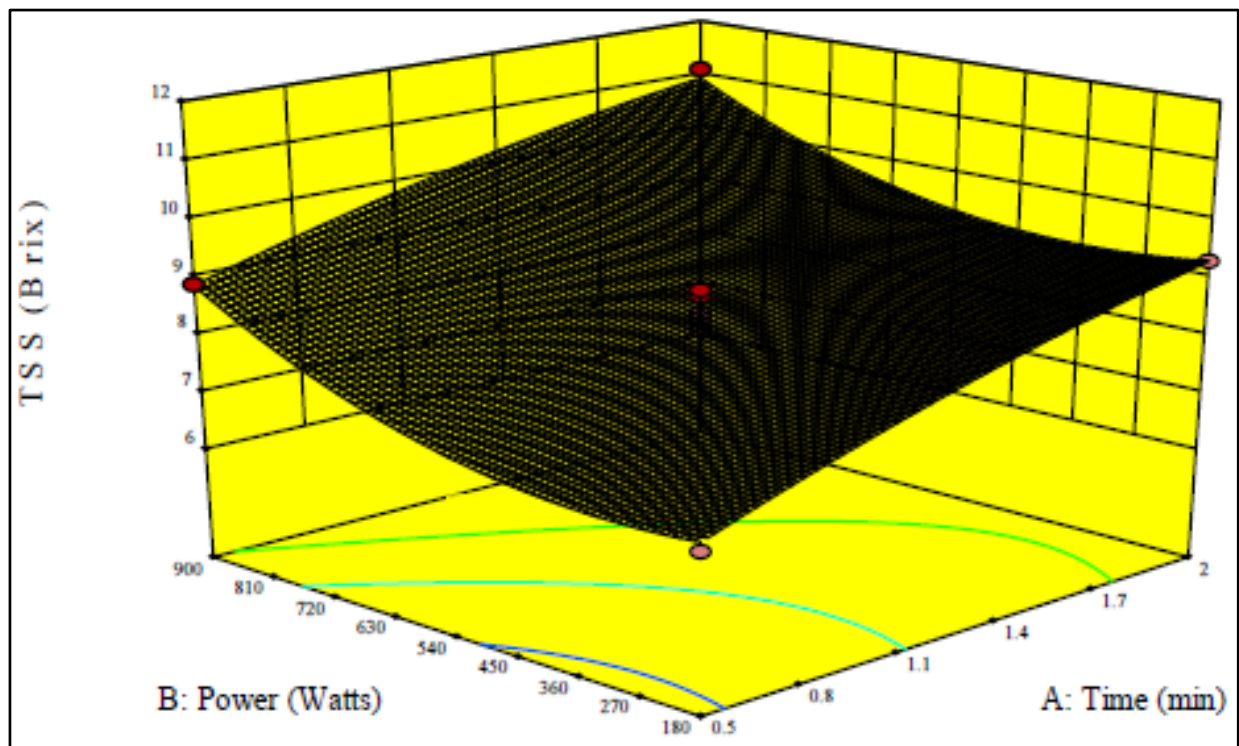

Fig 7: Response surface plot for TSS as a function of power and time (ratio kept constant at centre point).

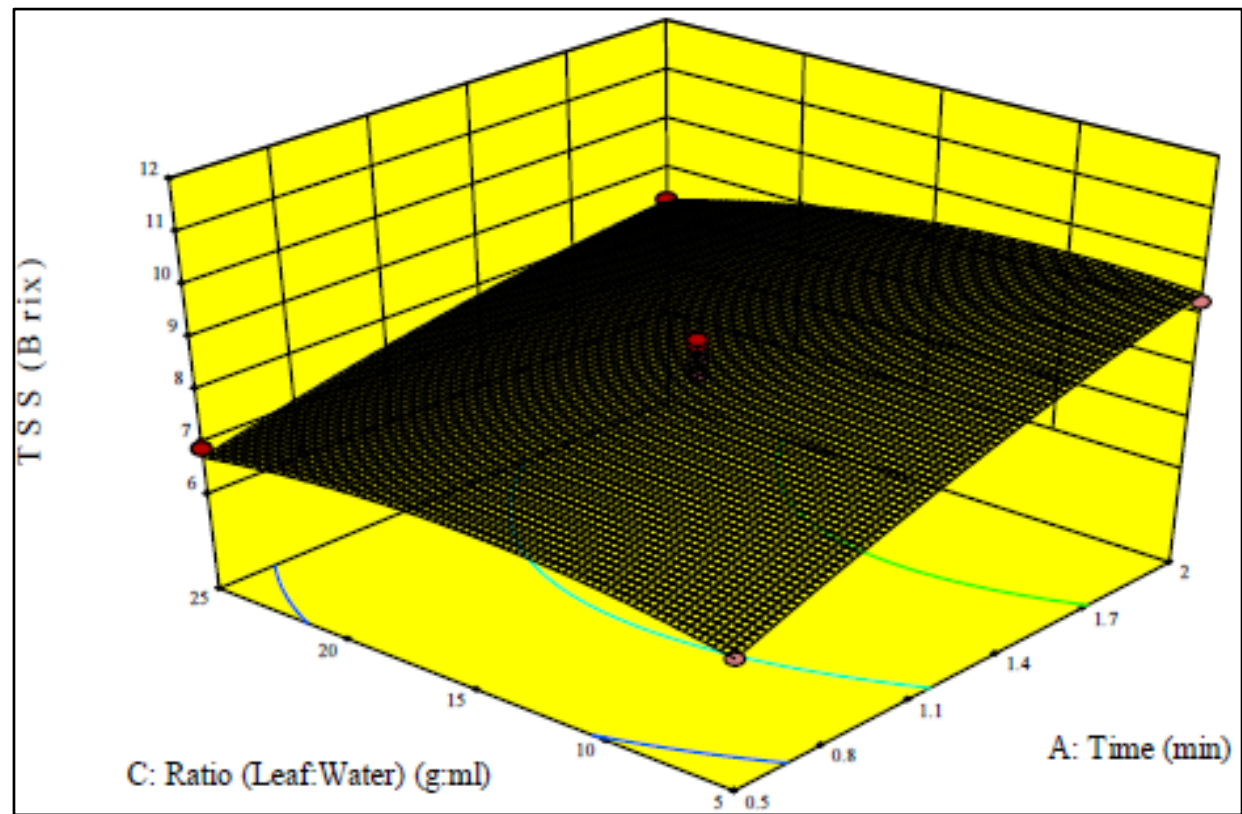

Fig 8: Response surface plot for TSS as a function of ratio and time (power kept constant at centre point).

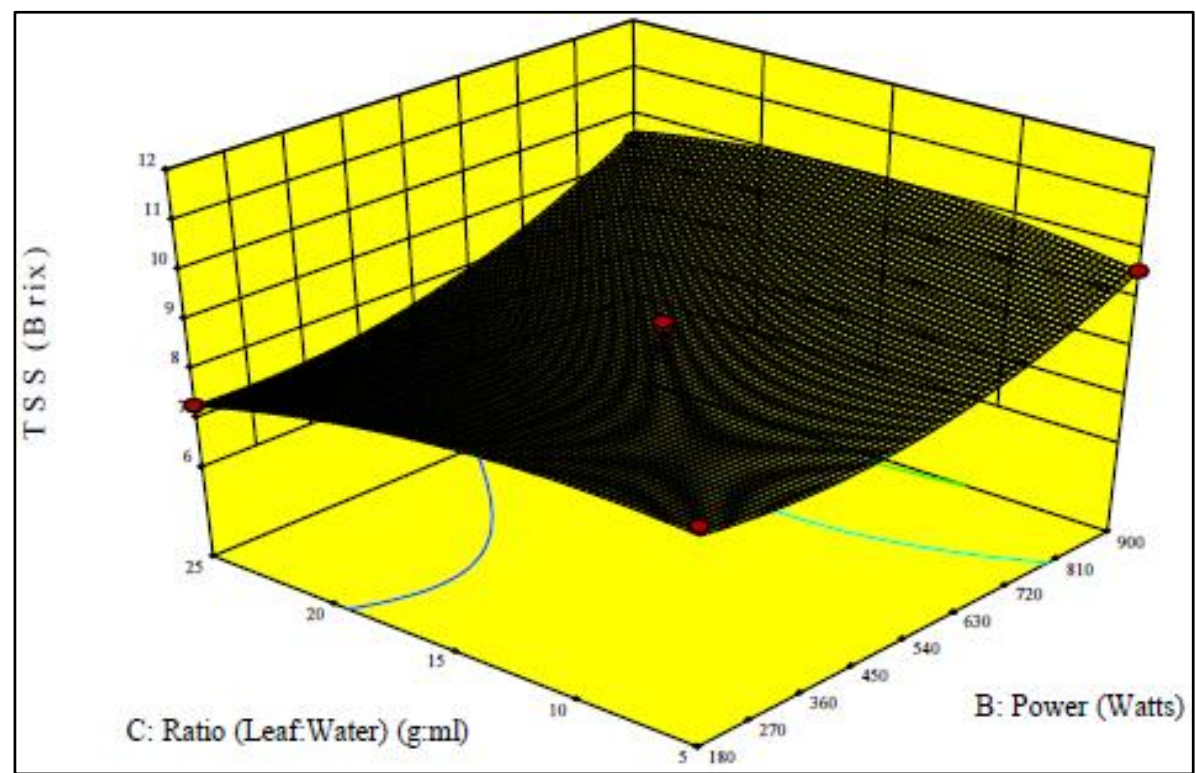

Fig 9: Response surface plot for TSS as a function of power and ratio (time kept constant at centre point). 


\section{Optimization}

The optimization of process factors was done using Design Expert software. Real-time optimizations of the various responses were executed using numerical optimization procedure of the software. The numerical optimization estimates a point that maximizes the desirability function. In this case, stevioside content was maximized and color was minimized and the TSS was kept in range. A solution having the highest desirability value (0.789) was selected as the optimum condition for extraction of maximum stevioside from dried stevia leaves. Optimized results according to design expert are given as: microwave power level: 454-watt, extraction time of heating: 1.13 minutes and leaf to water ratio: $1: 25(\mathrm{~g}: \mathrm{mL})$. The predicted values for stevioside content, color $\left(\mathrm{A}_{420}\right)$ and TSS were $9.37 \%, 1.16$ and 7.37 ${ }^{\mathrm{o}}$ Brix.

\section{Conclusion}

Stevioside extraction was significant at probability level $p<0.05$ and $p<0.01$ for first order terms of extraction time and microwave power level respectively. Color of stevia extract was significant at probability level $p<0.01$ for first order terms of microwave power level and power ratio. TSS of stevia extract was significant at probability level $p<0.01$ for first order terms of microwave power level and extraction time and significant at probability level $p<0.05$ for first order terms of ratio. The optimization analysis was done for optimization of process factors like microwave power level, extraction time and leaf to water ratio in order to maximize the extraction of stevioside from dry stevia leaf powder. Box and Behnken design was used for the purpose of experimental design. Statistical analysis and numerical optimization was executed by Design Expert Software. The optimum operating conditions for stevioside extraction are microwave power level 454 watt, time extraction time of heating 1.13 minutes and leaf to water ratio as 1:25 ( $\mathrm{g}: \mathrm{mL})$. At these optimum conditions, the quantity of stevioside extracted is $9.37 \mathrm{gm}$ per $100 \mathrm{~g}$ of dry stevia leaves.

\section{References}

1. Box GE, Behnken DW. Some new three level designs for the study of quantitative variables. Technometrics. 1960; 2(4):455-75.

2. Carakostas MC, Curry LL, Boileau AC, Brusick DJ. Overview: The history, technical function and safety of rebaudioside A, a naturally occurring steviol glycoside, for use in food and beverages. Food Chem Toxicol. 2008; 46: S1-S10.

3. Chranioti C, Chanioti S, Tzia C. Comparison of spray, freeze and oven drying as a means of reducing bitter aftertaste of steviol glycosides (derived from Stevia rebaudiana Bertoni plant)-Evaluation of the final products. Food chemistry. 2016; 190:1151-1158.

4. Dacome AS, Silva CC, Costa CEM. Sweet diterpenic glycosides balance of a new cultivar of Stevia rebaudiana (Bert.) Bertoni: isolation and quantitative distribution by chromatographic, spectroscopic, and electrophoretic methods. Process Biochem. 2005; 40:3587-94.

5. Dubois M, Gill KA, Hamilton TK, Robert PA, Smith F. Colorimetric method for determination of sugars \& related substances. Anal Chem. 1956; 28:350-56

6. Giovanetto RH. Method for the recovery of steviosides from plant raw material. US patent no. 1990; 4:892-938.

7. Kaur G. Biochemical composition \& characterization of glycoside of Stevia rebaudiana Bertoni at different development stages. MSc thesis, Punjab Agricultural University, Ludhiana, India, 2009.

8. Kumar S. Method for recovery of stevioside. US patent no. $1986 ; 4: 599403$.

9. Midmore JD, Rank AH. An intense natural sweetener laying the ground work for a new rural industry. RIRDC Publication No 06=020, RIRDC Project No UCQ-17A, Australia, 2006.

10. Pol J, Ostra EV, Karasek P, Roth M, Benesova K, Kotlarikova P. Comparison of two different solvents employed for pressurised fluid extraction of stevioside from Stevia rebaudiana: methanol versus water. Anal Bioanal Chem. 2007; 388:1847-57.

11. Tan S, Shibuta Y, Tanaka O. Isolation of sweetener from Stevia rebaudiana. Jpn Kokai, Patent no. 1988; 63:177764.

12. Yoda SK, Marques MOM, Petenate AJ, Meireles MAA. Supercritical fluid extraction from Stevia rebaudiana Bertoni using $\mathrm{CO} 2$ and $\mathrm{CO} 2+$ water: extraction kinetics and identification of extracted components. J Food Eng. 2003; 57:125-34. 